\title{
Trainee Readiness For Diversity Training
}

\author{
Yunhyung Chung, University of Idaho, USA
}

\begin{abstract}
Although trainee readiness is critical for diversity training effectiveness, extant research has not paid attention to the relationship between trainee readiness for diversity training and diversity training outcomes. This study identifies motivational, behavioral, and cognitive trainee readiness for diversity training and proposes a theoretical framework of how individual characteristics (perceived discrimination, demographic attributes, and previous diversity-related experience) and organizational characteristics (diversity climate and demographic dissimilarity) influence motivational, behavioral, and cognitive trainee readiness for diversity training.
\end{abstract}

Keywords: Diversity Training; Trainee Readiness; Diversity Climate; Pre-Training Reaction

\section{INTRODUCTION}

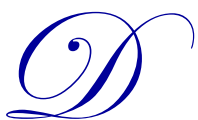

iversity initiatives in the workforce, especially diversity training programs, have become popular in organizations (Buzrukova, Jehn, \& Spell, 2012). In a 2010 SHRM survey, about 68 percent of US companies implement diversity training (Society for Human Resource Management, 2010). Thus, research on diversity has proliferated over the last decade. Most previous research has focused on the relationship between diversity training design - types and content - and training outcomes - reactions, learning, and training transfer - (see Kalinoski, Steele-Johnson, Peyton, Leas, Steinke, Bowling, in press for a meta-analytic review). These studies have an assumption regarding pre-training conditions - trainees attend diversity training programs under similar conditions. This assumption is unrealistic because training effectiveness can be largely affected by trainees' readiness for training (Noe, 2010). If trainees believe that a diversity training program will not be useful, they are not motivated to learn, and/or are ill-prepared, the success of the program is likely to be reduced. For example, trainees may not actively engage in diversity training and cannot improve diversity-related skills if they are not motivated to learn diversity-related skills before participating in a diversity training program. To fill the research gap, therefore, this study intends to enhance our understanding of trainee readiness for diversity training. Building on extant research on diversity and training, this study identifies three dimensions of trainee readiness for diversity training - motivational, behavioral, and cognitive. The first purpose of this study is to explain why and how these three dimensions of pre-training readiness for diversity training influence post-training outcomes.

The other purpose of this research is to develop a theoretical framework with regard to what individual and organizational characteristics may influence trainee readiness for diversity training. Unlike other types of training, the success of diversity training may be largely affected by trainees' multicultural experiences and views and contextual characteristics regarding diversity (Kulik, Pepper, Roberson, \& Parker, 2007). Without understanding these unique circumstances of diversity training, it is difficult to explain how to promote trainee readiness. Since demographic characteristics of individuals and groups and diversity climate may provide individuals more opportunities to think about diversity and to have more multicultural experiences, it is crucial to understand how they influence trainee readiness for diversity training.

\section{TRAINEE READINESS FOR DIVERSITY TRAINING}

The effectiveness of diversity training may depend on trainees' attitudes and reactions toward diversity training and diversity-related knowledge and skills before they actually attend a diversity training program. Drawing on previous training and diversity research, this study identifies motivational, behavioral, and cognitive readiness for diversity training. Motivational readiness for diversity training includes pre-training motivation to learn and pretraining self-efficacy. Behavioral readiness for diversity training includes pre-training intention to use the content of 
diversity and pre-training perceived utility. Cognitive readiness for diversity training includes pre-training knowledge, skills, and abilities regarding diversity. In this section, it is explained why and how motivational and behavioral readiness for diversity training may influence training outcomes such as reactions/behaviors, learning, and training transfer.

\section{Motivational Readiness for Diversity Training}

\section{Pre-Training Motivation to Learn}

Pre-training motivation to learn is defined as the trainees' desire to learn the content of a training program before they attend a training program (Facteau, Dobbins, Russell, Ladd \& Kudisch, 1995). Since trainees' pretraining motivation to learn can determine the focus and the level of effort in a training program, it is a focal factor that may enhance training effectiveness, especially learning outcomes and transfer (Warr \& Bunce, 1995; Wiethoff, 2004). Training research found that pre-training motivation to learn positively affects learning and transfer of training (Colquitt, LePine, \& Noe, 2000). If trainees are not highly motivated to learn the content of diversity training, they may not actively engage in the training program and cannot improve skills and knowledge regarding diversity (Mathieu, Tannenbaum \& Salas, 1992). Consequently, trainees who are not motivated to learn are less likely to transfer their knowledge and skills learned from the diversity training back to the job (Facteau et al., 1995).

Proposition 1a: Pre-training motivation to learn will be positively associated with diversity training outcomes such as post-training reactions and behaviors, learning, and transfer of training.

\section{Pre-Training Self-Efficacy}

Pre-training self-efficacy in diversity training refers to the degree of trainees' pre-training beliefs that they can learn and apply the content of diversity training. If trainees believe that they can master a great deal of knowledge and skills from diversity training programs (high pre-training self-efficacy), they will devote efforts to learning (Bandura, 1977). Training research has found a robust support on the positive effect of pre-training selfefficacy on training outcomes. If trainees have high self-efficacy, they are likely to be motivated to learn training content (Colquitt et al., 2000), enhance learning and utility of training (Warr \& Bunce, 1995), and improve job performance (Phillips \& Gully, 1997). Besides, a trainee's self-efficacy is stable and consistent over time; i.e., a high correlation between pre-training self-efficacy and mid-period self-efficacy (Mathieu, Tannenbaum \& Salas, 1992). Hence, pre-training self-efficacy may be positively associated with post-training self-efficacy and learning during training. In addition, since trainees with strong self-efficacy are likely to learn diversity training content, they are more likely to transfer their knowledge and skills to their jobs (Combs \& Luthans, 2007). Therefore, pre-training self-efficacy may be positively associated to post-training reactions, learning, and transfer of diversity training.

Proposition 1b: Pre-training self-efficacy will be positively associated with diversity training outcomes such as post-training reactions and behaviors, learning, and transfer of training.

\section{Behavioral Readiness for Diversity Training}

\section{Pre-Training Intention to Use Training Contents}

Pre-training intention to use the content of diversity training programs represents trainees' aim to use KSAs (knowledge, skills, and abilities) learned from the training programs. Ajzen (1991)'s theory of planned behavior suggests that an individual's intention to perform a given behavior can predict the actual behavior. The assumptions of the intention imply motivations that the individual is "willing to try hard and to exert efforts in order to perform the behavior" (p. 181). According to Ajzen's (1991) literature review, a large amount of evidence links intention to different types of behaviors (e.g. drinking, leisure, job search, and attending class). The theory of planned behavior applies to the effect of intention to use specific knowledge and skills gained from the training program. The degree of intention to use training content can predict whether the trainee performs specific behaviors in the on-the-job situation. That is, intention to use training contents is a critical variable for predicting actual behavior and training transfer. If an individual has enough intention to use the content of training in the pre-training phase, then the motivation may increase learning and influence her or his actual behavior in the post-training phase. 
Proposition 2a: Pre-training intention to use will be positively associated with diversity training outcomes such as post-training reactions and behaviors, learning, and transfer of training. Especially, they may be strongly associated with learning and transfer of knowledge and skills from diversity training.

\section{Pre-Training Perceived Utility}

Perceived utility of training contents refers to a trainee's belief or opinion of the training program to be useful for his/her job. If trainees find the content of training useful, they are more likely to apply the knowledge and skills learned from the training program to their jobs (Alliger, Tannenbaum, Bennet, Traver, \& Shorland, 1997). That is, pre-training perceived utility of diversity training may facilitate training transfer (Holladay \& Quiňones, 2005). In the pre-training phase, trainees judge through their current situation whether the training program has practical value. If trainees evaluate the practical value of diversity training highly, they are likely to actively engage in diversity training. Therefore, pre-training perceived utility of diversity may influence attitudes to transfer of training as well as learning.

Proposition 2b: Pre-training perceived utility will be positively associated with diversity training outcomes such as post-training reactions and behaviors, learning, and transfer of training. Especially, they may be strongly associated with learning and transfer of knowledge and skills from diversity training.

\section{Cognitive Readiness for Diversity Training}

The last dimension of trainee readiness for diversity training is cognitive readiness for diversity training. Training literature has shown that trainees' KSAs before attending a training program may improve learning because trainees who have low KSAs are incapable of learning new knowledge and skills (Noe, 2010). Research on diversity training literature has also highlighted the importance of trainees' KSAs. Kulik et al. (2007) found that employees who have high EEO knowledge and high cultural competence (behavioral or skill-based component of diversity training) are more likely to be interested in voluntarily attending a diversity training program. Since trainees with low diversity-related KSAs are even unaware of their skill deficits, they are not motivated to learn the content of diversity training and are not willing to use it at work. On the contrary, because trainees with high diversity-related KSAs are more interested in improving diversity-related KSAs, they are likely to be motivated to learn new knowledge and skills and to be willing to transfer them back to their jobs.

Proposition 3: Pre-training KSAs regarding diversity will be associated with diversity training outcomes such as post-training reactions and behaviors, learning, and transfer of training.

\section{THE INFLUENCE OF INDIVIDUAL AND ORGANIZATIONAL CHARACTERISTICS ON TRAINEE READINESS FOR DIVERSITY TRAINING}

This section identifies key individual and organizational characteristics that influence trainee readiness for diversity training. Since enhancing trainee readiness for diversity training is crucial for diversity training effectiveness, it is important to find key determinants of trainee readiness.

Previous research on diversity training has suggested that trainee characteristics and organizational contexts influence diversity training outcomes (see Bezrukova et al., 2012). For example, Holladay \& Quiňones (2005) found that trainees residing in individualistic cultures and in a higher job rank are more likely to perceive post-training usefulness of diversity training. Roberson, Kulik, \& Pepper (2009) found that trainee race and work unit transfer climate are associated with trainees' transfer strategy use. In addition, a large body of research on training has consistently argued and found that personal and organizational characteristics influence pre-training readiness as well as post-training outcomes (e.g., Baldwin \& Magjuka, 1997; Colquitt et. al., 2000).

Individual and organizational characteristics may influence pre-training readiness for diversity training in the same manner with other training. In that case, what individual and contextual factors may influence pre-training readiness for diversity training? In this paper, key individual and organizational characteristics, with regard to diversity, are identified and it is proposed that they may influence pre-training readiness for diversity training 
(Figure 1). A number of different individual and organizational characteristics may influence trainee readiness for diversity training. However, three individual characteristics (perceived discrimination, demographic attributes, and previous diversity-related experience) and two organizational characteristics (diversity climate and relational demography) are the focus because they are most relevant to the domain of diversity training.

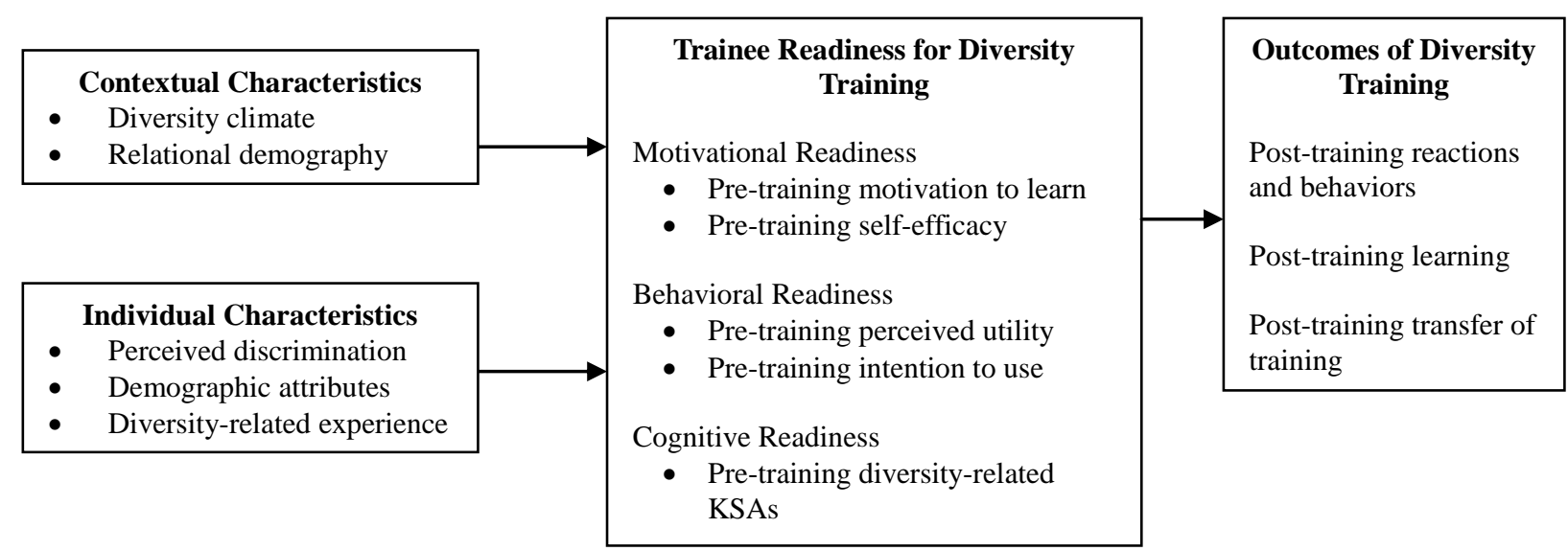

Figure 1: A Theoretical Framework of Trainee Readiness for Diversity Training

\section{Individual Characteristics and Trainee Readiness for Diversity Training}

Trainees' individual diversity characteristics, such as perceived discrimination, demographic attributes, and previous diversity-related experience, may play crucial roles to influence trainees' readiness for diversity training. Although previous research anticipated and found that people who perceive discrimination tend to have more positive reactions toward diversity training (Kossek \& Zonia, 1993; Mor Barak, et al., 1998), this explanation cannot fully explain its influence on trainee readiness for diversity training. This paper provides the theoretical rationale regarding how individual demographic attributes, perceived discrimination, and previous diversity-related experience influence positive reactions and attitudes toward diversity training.

\section{Influence on Motivational and Behavioral Readiness}

Social identity theory suggests that people categorize themselves into ingroups and others into outgroups based on demographic attributes. Through intergroup comparisons, they develop positive social identities for ingroups. The positive social identity may build ingroup bias in that group members regard their group as superior to other groups (ingroup favoritism). This individual perception of ingroup favoritism causes perceived intergroup discrimination (Ashforth \& Mael 1989; Brown, 2000). If an individual identifies a social identity based on his or her attributes, feels discriminated against, and has diversity-related experiences, s/he may have expectations about whether the skills and behaviors learned from diversity training decrease discrimination and unfair interpersonal treatments based on demographic attributes. Those individual expectations may be associated with motivation to learn, learning, performance, and behavioral change (Hicks \& Klimoski, 1987; Noe, 1986). If a trainee has high expectation regarding the effort-performance linkage, he or she may have high confidence to learn the content of diversity training (Noe \& Schmitt, 1986; Noe, 1986). Therefore, positive expectations about the outcome of diversity training may increase pre-training motivational readiness (pre-training motivation to learn and pre-training self-efficacy) for effective diversity training.

Adults tend to have higher motivation to learn when they recognize the practical value of learning (Blanchard \& Thacker, 1998). If trainees have experienced discrimination at work and have seen problems related to diversity, especially related to their jobs and work, they may think that learning how to solve those problems is practically important for their work (Smith-Jentsch, Jentsch, Payne, \& Salas. 1996). Thus, trainees may have higher pre-training motivation to learn the content of diversity training. In addition, if trainees think that they possess prior knowledge of discrimination, they may be less anxious about learning and may believe they have enough ability to learn. 
Pre-training intention to use content of diversity training and pre-training perceived utility of diversity training may be positively influenced by perceived discrimination and diversity-related experience as well. Trainees are willing to use the training content at their workplace when they think that diversity training will improve the workplace where discrimination exists. If trainees find the practical value of diversity training programs and think that diversity training helps them effectively perform, they may favorably perceive the utility of the diversity training. Therefore, perceived discrimination, demographic attributes, and previous diversity-related experience may be positively associated with behavioral readiness for diversity training.

\section{Influence on Cognitive Readiness}

If trainees perceive a social identity based on their attributes, feel discriminated against at work, and/or have diversity-related experience, they are more likely to have KSAs about diversity. Trainees who perceive discrimination may be familiar with the key concepts, real situations, and problems because discrimination is a major topic of diversity training programs. For example, if trainees have experienced discrimination or observed discriminatory events, they may better understand when they encounter illustrations of discrimination during the diversity training. They also have had more opportunities to contemplate diversity issues in order to respond to their problems effectively than other trainees who do not have diversity-related experiences. Therefore, perceived discrimination, demographic attributes, and previous diversity-related experience may be positively associated with cognitive readiness for diversity training.

Proposition 4: Trainee characteristics (perceived discrimination, demographic attributes, and previous diversityrelated experience) may affect motivational, behavioral, and cognitive readiness for diversity training. Specifically, trainees who perceive discrimination, are minorities, and have prior diversity-related experiences may have a higher level of motivational, behavioral, and cognitive readiness for diversity training than those who do not perceive discrimination, are majorities, and do not have prior diversity-related experiences.

\section{Contextual Characteristics and Trainee Readiness for Diversity Training}

Diversity climate and relational demography may trigger trainees' needs for diversity training and consequently shape readiness for diversity training. Diversity climate has been identified as a critical factor to improve organizational performance by ensuring that employees are fairly treated regardless of demographic backgrounds (Ely \& Thomas, 2001). Employees who perceive a supportive organizational climate may affect their cognitive and affective states, such as job motivation (Chung, Liao, Subramony, Jackson, Colakoglu, \& Jiang, 2011; Kopelman, Brief, \& Guzzo, 1990). Relational demography refers to the degree of similarity of the attributes between an individual and other group members (Perry, Kulik, \& Zhou, 1999). It includes not only collective relations between an individual and peers, but also dyadic relations between a subordinate and a supervisor. Studies on the various effects of relational demography have used the similarity-attraction paradigm. If people have similar attitudes (e.g., physical, social, and status traits) with other group members, they tend to have greater attraction to group members (Byrne, 1971). However, if people do not have similar attributes with other group members, they are likely to leave the group and/or have less cohesion (Guillaume, Brodbeck, \& Riketta, 2012). Therefore, demographic similarity may lead to perceived similarity in attitudes and values and is likely to affect interpersonal attraction between an individual and peers or between a supervisor and a subordinate (e.g., Tsui \& O'Reilly, 1989) and employee reactions (citizenship, absenteeism, work change behaviors) (Perry, et. al., 1999).

Diversity climate and relational demography are important factors that may affect trainee readiness for diversity training. Trainees in an organization with high demographic dissimilarity and an unfavorable diversity climate may feel the need for diversity training. In addition, they may think that diversity training is important in the organization because they undergo more social conflicts in a diverse demographic group and may feel unfairly treated due to demographic background.

\section{Influence on Motivational and Behavioral Readiness}

The similarity-attraction paradigm suggests that if an individual's attributes are different from a supervisor's or peers' attributes, they are less likely to interact with each other. In the work context of high demographic 
dissimilarity between an individual and a supervisor and between an individual and peers in the group, s/he may expect low supervisor and peer support. If trainees experience low attachment and interactions with a supervisor or peers, they may feel the need for diversity training to improve the situation and may expect diversity training to be useful. In addition, if trainees feel that organizational diversity climate is unfavorable (i.e., employees are not fairly treated regardless of demographic background), they are more likely to feel the need for behavioral and attitudinal changes in the organization. Since trainees who are under high demographic dissimilarity and poor diversity climate may have relevant experience regarding diversity issues, they are more likely to believe that they can learn the content of diversity training very well. Hence, demographic dissimilarity and an unsupportive diversity climate may increase motivational readiness for diversity training. In addition, demographic dissimilarity and diversity climate may favorably influence behavioral readiness for diversity training. If individuals confront a problem such as a social conflict, they may be willing to use the knowledge and skills in real situations (pre-training intention to use) in order to resolve the problems and may feel the knowledge and skills useful (pre-training perceived utility).

\section{Influence on Cognitive Readiness}

Demographic dissimilarity and diversity climate may be regarded as prior experience related to the content of diversity training. Individuals who are under dyadic and group dissimilarity and a poor diversity climate may be familiar with key concepts, real situations, and problems regarding diversity. For example, if individuals experience social conflict due to dissimilar attributes with a supervisor or peers and observe an unsupportive diversity climate, they may have more opportunities to think about problems due to diversity-related conflicts and may develop skills and knowledge to cope with the problems. Therefore, demographic dissimilarity and an unsupportive diversity climate may increase cognitive readiness for diversity training.

Proposition 5: Organizational characteristics (diversity climate and relational demography) may affect motivational, behavioral, and cognitive readiness for diversity training. Specifically, trainees who work in organizations having a favorable diversity climate and high demographic dissimilarity may have a higher level of motivational, behavioral, and cognitive readiness for diversity training than those who do not work in such organizations.

\section{DISCUSSION}

Although diversity training has been very popular in the US, cynicism about diversity training has been increasing (Roberson, Kulik, \& Tan, 2013). The cynicism is rooted not merely in the problems with design (i.e., content and instructional methods) of diversity training but also in misunderstanding of the unique circumstances regarding determinants of diversity training effectiveness. To enhance understanding of determinants of diversity training effectiveness, investigating trainee readiness for diversity training is important. This study contributes to research on diversity training by identifying trainee motivational, behavioral, and cognitive readiness for diversity training that is relatively neglected in previous research. In addition, this study extends previous diversity training literature by explaining how individual and organizational characteristics with regard to diversity influence trainee readiness for diversity training.

This study also provides several practical suggestions to organizations and diversity trainers. First, organizations and trainers should assess person need analyses more thoroughly to assess motivational, behavioral, and cognitive readiness for diversity training in order to improve diversity training outcomes. Second, organizational needs analyses are also critical because demographic dissimilarity and diversity climate may determine the level of motivational, behavioral, and cognitive readiness for diversity training. Third, this study suggests that diversity training alone cannot improve diversity climate. Organizations should ensure providing fair HR practices and promote a positive diversity climate to improve the effectiveness of diversity training. Fourth, at the beginning of the diversity training, setting up clear goals and helping trainees be aware of the importance of learning diversity skills may improve trainee readiness for diversity training. Last, voluntary participation in diversity training may reduce resistance to diversity training and improve readiness for diversity training. 


\section{AUTHOR INFORMATION}

Yunhyung Chung, is an Assistant Professor of Management and Human Resources at University of Idaho. She received her Ph. D. from Rutgers University. She has published articles in Journal of Management, Journal of Management Education, Journal of Trust Research, and Research in Personnel and Human Resource Management. E-mail: yunchung@uidaho.edu

\section{REFERENCES}

1. Ajzen, I. (1991). The theory of planned behavior. Organizational Behavior and Human Decision Processes, 50, 179-211.

2. Alliger, G. M., Tannenbaum, S. I., Bennett Jr. W., Traver, H. \& Shotland, A. (1997). A meta-analysis of the relations among training criteria; Personnel Psychology, 502, 341-358.

3. Ashforth, B. E., \& Mael, F. (1989). Social identity theory and the organization. Academy of Management Review, 14, 20-39.

4. Baldwin, T., \& Magjuka, R. (1997). Training as an organizational episode: Pretraining influences on trainee motivation. In. K. Ford \& Associates Ed. Improving Training Effectiveness in Organizations. pp. 99-127. Mahwah, NJ: LEA.

5. Blanchard, P. N. \& Thacker, J. W. (1998). Effective training: Systems, strategies, and practices. New Jersey: Prince Hall.

6. Brown, R. (2000). Social identity theory: Past achievements, current problems and future challenges. European Journal of Social Psychology, 30, 745-778.

7. Buzrukova, K., Jehn, K. A., \& Spell, C. S. (2012). Reviewing diversity training: Where we have been and where we should go. Academy of Management Learning \& Education. 11, 207-227.

8. $\quad$ Byrne, D. (1971). The attraction paradigm. New York: Academic Press.

9. Chung, Y., Liao, H., Subramony, M. A., Jackson, S. E., Colakoglu, S., \& Jiang, Y. A. (2011). A cross-level analysis of demographic faultlines and diversity climate on job dedication. The 2011 Academy of Management Best Papers Proceeding.

10. Colquitt, J. A., LePine, J. A. \& Noe, R. A. (2000). Toward an integrative theory of training motivation: A meta-analytic path analysis of 20 years of research. Journal of Applied Psychology, 855, 678-707.

11. Combs, G. M., \& Luthans, F. (2007). Diversity training: Analysis of the impact of self-efficacy. Human Resource Development Quarterly, 18: 91-120.

12. Ely, R. J. \& Thomas, D. A. (2001). Cultural diversity at work: The effects of diversity perspectives on work group processes and outcomes. Administrative Science Quarterly, 46: 229-273.

13. Facteau, J. D., Dobbins, G. H., Russell, J. E. A., Ladd, R. T., \& Kudisch, J. D. 1995. The influence of general perceptions of the training environment on pretraining motivation and perceived training transfer. Journal of Management, 21, 1-25.

14. Guillaume, Y. R. F., Brodbeck, F. C., \& Riketta, M. (2012). Surface- and deep-level dissimilarity effects on social integration and individual effectiveness related outcomes in work groups: A meta-analytic integration. Journal of Occupational \& Organizational Psychology. 85, 80-115.

15. Hicks, W. D. \& Klimoski, R. J. (1987). Entry into training programs and its effects on training outcomes: A field experiment. Academy of Management Journal, 303, 542-552.

16. Holladay, A. L., \& Quiňones, M. A. (2005). Reactions to diversity training: An international comparison, Human Resource Development Quarterly, 16, 529-545.

17. Kalinoski, Z. T., Steele-Johnson, D., Peyton, E. J., Leas, K. A., Steinke, J., \& Bowling, N. A. A metaanalytic evaluation of diversity training outcomes. Journal of Organizational Behavior, in press.

18. Kossek, E. E. \& Zonia, S. C. (1993). Assessing diversity climate: A field study of reactions to employer efforts to promote diversity. Journal of Organizational Behavior, 14, 61-81.

19. Kulik, C. T., Pepper, M. B., Roberson, L., \& Parker, S. K. (2007). The rich get richer: Predicting participation in voluntary diversity training. 28, 753-769.

20. Mathieu, J. E., Tannenbaum, S. I. \& Salas, E. (1992). Influences of individual and situational characteristics on measures of training effectiveness. Academy of Management Journal, 354, 828-847. 
21. Mor Barak, M. E., Cherin, D. A. \& Berkman, S. (1998). Organizational and personal dimensions in diversity climate: Ethnic and gender differences in employee perceptions, The Journal of Applied Behavioral Science, 341, 82-104.

22. Noe, R.A. \& Schmitt, N. (1986). The influence of trainee attitudes on training effectiveness: Test of a model, Personnel Psychology, 39, 497-523.

23. Noe, R.A. (1986). Trainees' attributes and attitudes: neglected influences on training effectiveness, Academy of Management Review, 114, 736-749.

24. Noe, R.A. (2010). Employee Training and Development. Irwin/McGraw-Hill Companies, Inc.

25. Perry, E. L., Kulik, C. T. \& Zhou, J. (1999). A closer look at the effects of subordinate-supervisor age differences. Journal of Organizational Behavior, 20, 341-357.

26. Phillips, J. M., \& Gully, S. M. (1997). The role of goal orientation, ability, need for achievement, and locus of control in the self-efficacy and goal setting process. Journal of Applied Psychology, 825, 792-802.

27. Roberson, L., Kulik, C. T., \& Pepper, M. B. (2009). Individual and environmental factors influencing the use of transfer strategies after diversity training. Group and Organization Management, 34, 67-89.

28. Roberson, L., Kulik, C. T., \& Tan, R. Y. (2013). Effective diversity climate. The Oxford Handbook of Diversity and Work, 341-365.

29. Smith-Jentsch, K. A., Jentsch, F. G., Payne, S. C, \& Salas, E. (1996). Can pretraining experiences explain individual differences in learning? Journal of Applied Psychology, 811, 110-116.

30. Society for Human Resource Management (2010). SHRM research spotlight: Workplace diversity practices poll. Retrieved from http://www.shrm.org/Research/SurveyFindings/Articles/Documents/DiversityFlier_FINAL_spotlight.pdf

31. Tracey, J. B., Hinkin, T. R., Tannenbaum, S. I. \& Mathieu, J. E. (2001). The influence of individual characteristics and the work environment on varying levels of training outcomes. Human Resource Development Quarterly, 12(1), 5-23.

32. Tsui, A. S. \& O'Rreilly III., C. A. (1989). Beyond simple demographic effects: The importance of relational demography in superior-subordinate dyads. Academy of Management Journal, 32, 402-423.

33. Warr, P. \& Bunce, D. (1995). Trainee characteristics and the outcomes of open learning. Personnel Psychology, 482, 347-376.

34. Wiethoff, C. (2004). Motivation to learn and diversity training: Application of the theory of planned behavior. Human Resource Development Quarterly, 15, 263-278. 